\title{
Preliminary comparison between the roles of support workers and social workers in community mental health services
}

\section{Barnaby Pace}

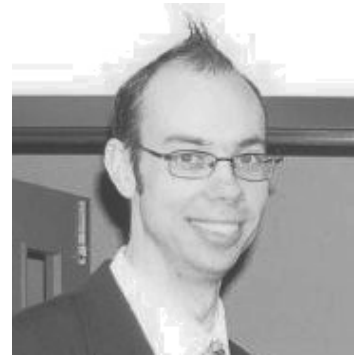

\begin{abstract}
Barnaby has worked in the mental health sector for the past 10 years. In this time he has held numerous positions ranging from a residential support worker through to a clinical team member. Currently he is lecturing for WINTEC on their Mental Health and Social Services programmes.
\end{abstract}

\begin{abstract}
Within New Zealand there is a definite confusion between the role identity of social workers and support workers within community mental health services. Currently there appears to be a degree of confusion as to the distinguishing features of these two roles. The objective of this preliminary investigation was to identify the similarities and differences within the two discipline areas. The themes identified through the thematic analysis indicated marked similarities between the two roles examined. The fundamental differences identified were the level of qualification, competencies, clinical work and experience of the workers. Scopes of practice are considered as a means of offering individual identities for both disciplines.
\end{abstract}

\section{Introduction}

Within New Zealand's health care sector there is confusion between the role identity of social workers and support workers. This confusion appears to result from the inability of professionals and service users to distinguish the key features of these two roles. According to the Ministry of Health (Brown, Wells, \& Scott, 2006) demands on health services between 2001 and 2021 are going to increase substantially, and of the current mental health workforce there are an estimated 1,432 support workers and 311 social workers (Ministry of Health, 2005). Taking these figures into consideration it appears that support workers make up a large part of our health system workforce, second only to nurses $(\mathrm{N}=3,052)$, and what they actually do in the system far outweighs their job description (Pace, 2009a; 2009b). The Ministry of Health (2005; Brown, Wells, \& Scott, 2006) also acknowledges there is a shortage of both regulated and unregulated personnel in the workforce in which support workers are included (Baldwin, Roberts, Fitzpatrick, While, \& Cowan, 2003). The author believes the confusion is the result of the over burdened health care sector and the need for paraprofes- 
sional staff to 'fill the gaps' in service delivery, a concern echoed by Mackenzie (2006) through the investigation of employing paraprofessional staff to reduce staff workloads.

Recent research conducted by Galloway \& Smith (2005) state that 'job titles for support workers are numerous and reflect the ambiguity of what the role encompasses', with several research articles indicating the same perspective (Baldwin, et al., 2003; Pace, 2009a). Similarities have been found when studying social worker roles stating that ambiguous role definitions allow roles to blur and may lead to conflict when members of different professions see themselves as performing the same functions or providing similar services (Davidson, 1990).

The role of a support worker is not clearly defined and it would appear that support workers are doing many jobs outside of their current job descriptions (Pace, 2009a). This may be due to a number of factors, including the aforementioned shortages of staff and increased demands on services. Like social workers it appears support workers are not being recognised for the diversity of duties they perform, many of which support workers perceive as the functions of social work practice. This role confusion between paraprofessionals, such as support workers, and professionals can lead to conflict in the workplace. Therefore if support workers were recognised more appropriately for the work they do it is hypothesised that there wouldn't be the conflict that currently appears present between these two disciplines. The objective of this preliminary investigation is to identify and examine the roles and responsibilities, and qualifications of both social workers and support workers in mental health services. The research will endeavour to clarify the differences and similarities between social work and support work in order to determine if further investigation is required.

\section{Method}

Selection criterion used for the current research stated that the agencies provided mental health/psychiatric recovery and rehabilitation services, which employed social workers and paraprofessionals in the role of support workers. Eight organisations meet this criterion. The sample comprised of five community-based non-government organisations (NGOs), two clinical-based government agencies, and a Kaupapa Maori-based NGO.

A thematic analysis (Braun \& Clarke, 2006) was conducted across 16 New Zealand job descriptions for community-based mental health social workers and support workers. Common themes in the roles and responsibilities, and knowledge and skills were identified and compared, with required qualifications additionally acknowledged. The commonly occurring themes for both disciplines were compared for similarities and subsequent differences.

\section{Results}

The themes identified through the thematic analysis indicated marked similarities between the two roles examined. The fundamental differences identified were the level of qualification, competencies, clinical work and experience of the workers (Table 1.). Social workers required at least a bachelors level qualification and a minimum of two years' experience, standard requirements of social worker registration in New Zealand, whereas with support workers there was no minimum qualification, or level of experience. However, there 
was a recommendation for support workers to hold a National Certificate in Mental Health (Mental Health Support Work).

Clinical-based tasks, including referrals, assessment, information collection and report writing featured strongly in social work job descriptions, but not in support work. Similarly, analytical and evaluation skills were identified requirements for social work only. Neither were stated requirements of support work.

Noticeably within the social worker job description there is a clear registration requirement, with subsequent reference to scopes of practice and code of conduct. There was no reference to either in the support worker information.

Table 1. Role comparison between social workers and support workers.

\begin{tabular}{|c|c|c|}
\hline \multirow{15}{*}{$\begin{array}{l}\text { Role } \\
\text { and } \\
\text { Responsibilities }\end{array}$} & Social workers & Support workers \\
\hline & Responsible to a manager & Responsible to a manager \\
\hline & Provide professional services & Provide professional services \\
\hline & $\begin{array}{l}\text { Protocols, incident reports, } \\
\text { standards of service, values }\end{array}$ & $\begin{array}{l}\text { Protocols, incident reports, } \\
\text { standards of service, values }\end{array}$ \\
\hline & Objectives: Meeting KPI & Objectives: Meeting KPI \\
\hline & Health and safety & Health and safety \\
\hline & Professional development & Professional development \\
\hline & $\begin{array}{l}\text { Information gathering, reports, } \\
\text { updating resources }\end{array}$ & \\
\hline & $\begin{array}{l}\text { Good personal conduct and staff } \\
\text { relationships }\end{array}$ & $\begin{array}{l}\text { Good personal conduct and staff } \\
\text { relationships }\end{array}$ \\
\hline & Supervision & Supervision \\
\hline & Networking & Networking \\
\hline & Clinical referral & \\
\hline & Advocacy and support & Advocacy and support \\
\hline & Teaming meetings & Teaming meetings \\
\hline & $\begin{array}{l}\text { Liaison with clinical and } \\
\text { governmental departments }\end{array}$ & \\
\hline \multirow{7}{*}{$\begin{array}{l}\text { Skills and } \\
\text { Knowledge }\end{array}$} & Communication and listening skills & Communication and listening skills \\
\hline & Planning and organisational skills & Planning and organisational skills \\
\hline & $\begin{array}{l}\text { Understanding of social and cultural } \\
\text { issues }\end{array}$ & $\begin{array}{l}\text { Understanding of social and } \\
\text { cultural issues }\end{array}$ \\
\hline & Analytical and evaluative skills & \\
\hline & Assessments & \\
\hline & Culturally sensitive & Culturally sensitive \\
\hline & Client confidentiality & Client confidentiality \\
\hline Qualification & $\begin{array}{l}\text { Degree level qualification in } \\
\text { social work } \\
\text { Social worker registration } \\
\text { Two years' work experience }\end{array}$ & $\begin{array}{l}\text { National Certificate in Mental } \\
\text { Health (Mental Health Support Work } \\
\text { (recommended only) }\end{array}$ \\
\hline
\end{tabular}




\section{Discussion}

After collecting and collating job descriptions for both social workers and support workers, the results suggest that roles/ responsibilities, skills and knowledge for both disciplines are indeed similar. However, differences are evident in qualification type and clinical skill requirements. Whilst the role of the support worker is not clearly defined in research models, the same expectations of duties performed within the regulated and unregulated workforce provides the same professional attributes and creates a very fine line between both disciplines. Support workers seem to come under the category of caregivers or paraprofessionals, suggesting the role is less clinical in its nature.

Social workers come under their own jurisdiction as a professional body who have a registration board agency with whom they can be registered and are usually connected to a government agency. Within the realms of the community in which both parties work, the functions and the jobs or tasks that are performed are comparable. The understanding of the work performed by a social worker appears to be held in a higher regard by the professional arena. However, ambiguous role definitions allow these roles to blur and support workers are increasingly having to come under the same job descriptions as social workers even though they are not qualified or registered to do so.

One outstanding difference indicated by the research was the qualification and registration requirements. To provide professional services social workers are required to have a degree-level qualification in social work and at least two years' work experience in the field, whereas mental health support workers have no required qualification level. Agencies are currently driving for a change in this regard, however, looking towards setting the National Certificate in Mental Health (Mental Health Support Work) as a base requirement. Additionally, funding bodies for NGOs are now introducing a requirement that a base-level qualification is expected by staff members working in a social support role. Meanwhile the expectations of work professionalism within community sectors are under the same umbrella and are recognised as the same roles and functions pertaining to social work. All workers need to have the same analytical and evaluative skills to provide the same competency and understanding of practice.

Whilst support workers may perceive that they engage in the same tasks as social workers (Pace, 2009a), and indeed they may, the second point of difference identified in this investigation indicates otherwise. Clinical tasks and associated skills / competencies were only seen in the social worker job descriptions used in this investigation, suggesting that clinical-based functions are not a part of mental health support work. The level of skill/competence for support workers is reflected by the associated qualification, offering further evidence that support work is a non-clinical discipline.

Multiple questions can be raised based on these preliminary findings including:

- Does the social workers' and support workers' identification need to be examined and changed?

- Why do the ambiguous roles overlap but qualifications in each sector differ?

- Why are social workers' and support workers' job descriptions categorised in the same text? 
- Do the Government and educational bodies now need to regulate the structure to incorporate position titles as one, being social work? Do the regulations on qualifications and registrations for social work and support work need to be structured as one?

Some of these questions are now being considered in light of recent discussions among registered social workers with regards to the inclusion of associate memberships for support workers who have completed appropriate qualifications and levels of clinical skill.

The consideration of associate membership within the social work scope of practice would offer a clear identification and solution to the issues raised within this paper. The associate membership could form the foundation for a subcategory of social work: Supportive social work/recovery-focused social work. The development of such concepts would professionalise support work whilst enhancing the field of social work by offering an additional scope of practice, in essence formalising what is already occurring within the mental health workforce. Further research focused on determining the function and relationship of these two disciplines is, however, required. Task analysis centred on both disciplines would offer a great source of information for further comparison providing a clearer indication of the similarities between the practice of social work and support work within the mental health sector.

Acknowledgements. The author would like to acknowledge G. Cherrington, H. Falconer, R. Lyngard and J. Rouse for their initial work within this investigation.

\section{References}

Baldwin, V., Roberts, J.D., Fitzpatrick, J.I., While, A., \& Cowan, D.T. (2003). The role of the support worker in nursing homes: A consideration of key issues. Journal of Nursing Management, II(6), 410-421.

Braun, V., \& Clarke, V. (2006). Using thematic analysis in psychology. Qualitative Research in Psychology, 3, 77-101.

Brown, M. O., Wells, J. E., \& Scott, K. M. (2006). Te rau hinengaro: The New Zealand mental health survey. Ministry of Health, Wellington: New Zealand.

Davidson K.W. (1990). Role blurring and the hospital social workers search for a clear domain. Health and Social Work, 15(3), 228-234.

Galloway, J., \& Smith, B. (2005). Meeting the education and training needs of rehabilitation, support workers. International Journal of Therapy and Rehabilitation, 12(5), 195-198.

Mackenzie, M. (2006). Benefits or burden: Introducing paraprofessional support staff to health visit teams. The case of Starting Well. Health and Social Care in the Community, 14(6), 523-531.

Ministry of Health. (2005). Tauawhitia te Wero - Embracing the challenge: National mental health and addiction workforce development plan 2006-2009. Wellington: Ministry of Health.

Pace, B. (2009a). How New Zealand community mental health support workers perceive their role. International Journal of Psychosocial Rehabilitation, 13(2), 5-10.

Pace, B. (2009b). Organisational views of the mental health support worker role and function. Unpublished paper. Waikato Institute of Technology, New Zealand. 